\title{
A Closure Look at the Pregnancy-Associated Arterial Dissection
}

\author{
Cechuan Deng ${ }^{1,2}$, Han Wang ${ }^{1}$, Xiangqi Chen ${ }^{1}$ and Xiaoqiang Tang ${ }^{1 *}$ \\ ${ }^{1}$ Key Laboratory of Birth Defects and Related Diseases of Women and Children of MOE, State Key Laboratory of Biotherapy, \\ West China Second University Hospital, Sichuan University, Chengdu, China, ${ }^{2}$ Department of Obstetrics and Gynecology, \\ West China Second University Hospital, Sichuan University, Chengdu, China
}

Keywords: pregnancy, arterial dissection, risk facors, diabetes, metabolism

\section{INTRODUCTION}

Cardiovascular diseases have become the first leading cause of morbidity and mortality (Chen et al., 2020a,b; Tang et al., 2020). Cardiovascular and metabolic syndrome are common in pregnant patients (Li et al., 2017; Timpka et al., 2018). Among cardiovascular diseases, arterial dissection is a severe vascular disease with high-mortality in pregnant patients (Ramlakhan et al.,

\section{OPEN ACCESS}

Edited by:

Venkaiah Betapudi,

United States Department of Homeland Security, United States

Reviewed by:

Alberto Maud,

Texas Tech University Health Sciences Center El Paso, United States

Hiroaki Tanaka,

Mie University, Japan

*Correspondence:

Xiaoqiang Tang

tangxiaoqiang@scu.edu.cn;

txiaoqiang@yeah.net

Specialty section:

This article was submitted to

Cellular Biochemistry,

a section of the journal

Frontiers in Cell and Developmental

Biology

Received: 26 January 2021

Accepted: 22 February 2021

Published: 12 March 2021

Citation:

Deng $C$, Wang $H$, Chen $X$ and Tang $X$ (2021) A Closure Look at the Pregnancy-Associated Arterial

Dissection.

Front. Cell Dev. Biol. 9:658656. doi: 10.3389/fcell.2021.658656 2020). Arterial dissection is a common cause of arterial disease after atherosclerosis (Adlam et al., 2016). The cause of this arterial disease is not fully understood. Analysis of the risk factors, epidemiology, and mechanisms of pregnancy-associated arterial dissections are important.

\section{RISK FACTORS OF PREGNANCY-ASSOCIATED ARTERIAL DISSECTION}

During the past decades, a large number of studies tried to figure out the key risk factors for pregnancy-associated arterial dissection. Hemodynamic and hormone changes during the perinatal period increase the risk factors of arterial dissection (Habashi et al., 2019; Al-Hussaini, 2020). Most previous studies have linked patients with underlying connective tissue diseases such as Marfan and Ehrlers-Danlos syndrome (Al-Hussaini, 2020). With a large population-based database of admissions, Beyer et al. provided a comprehensive analysis of the occurrence and risk factors of dissection within the peripartum period in pregnancy patients (Beyer et al., 2020). Beyer et al. statistically analyzed the occurrence of dissection during the peripartum period and explored the risk factors, time, location, and in-hospital mortality of dissection during the peripartum period. The result showed that $0.005 \%$ of pregnancy-related dissections occurred, and the most common diagnosis time point and location were during the postpartum period and coronary, respectively. The mortality of pregnant women with dissections in the hospital was higher than that of pregnant women without dissections, and the mortality of aortic dissection was the highest (8.6\%). Most studies before only studied aortic dissection and spontaneous coronary artery dissection (SCAD) in pregnant women, while the relationship between arterial dissections other than aortic dissection and SCAD and pregnancy has been poorly studied. This excellent study has provided timely and comprehensive information but also left some discussion space.

\section{GESTATIONAL DIABETES-THE LEADING RISK FACTOR?}

Based on the data of this study, gestational diabetes is the leading risk factor for pregnancy-associated arterial dissections. Interestingly, this study provided new data that gestational diabetes leads to a 65 -fold increase in risk for arterial dissections during pregnancy. This 
finding highlights the importance of blood glucose control for pregnant patients and leaves the question that whether blood glucose intervention can reduce the risk of arterial dissections. However, previous studies revealed that diabetes mellitus is remarkably uncommon in patients with thoracic aortic dissection (LeMaire and Russell, 2011; Theivacumar et al., 2014). Besides, according to a Japan survey, aortic dissection has not occurred in women with gestational diabetes (Katsuragi et al., 2011). The risk of gestational diabetes to different types of arterial dissections may be different. A further complementary study may include this information.

\section{OTHER CONFOUNDING FACTORS}

The authors included many complications/risk factors, and we also suggest analyzing some other risk factors. (a) Inflammatory reactions, including systemic lupus erythematosus and multiple nodular arteritis, can increase the risk of arterial dissections in women (Tweet et al., 2018). (b) In addition to the EhlersDanlos syndrome and Marfan syndrome listed in this article, some other connective tissue diseases, such as the Loeys-Dietz syndrome, are also related to arterial dissections (Ramlakhan et al., 2020). (c) Also, hereditary arterial disease (e.g., hereditary hypertension) is a risk factor for arterial dissections, and about $5 \%$ of female arterial dissections patients have hereditary arterial disease (Collet et al., 2020; Ramlakhan et al., 2020). Although the vast majority of the arterial dissection in the supra-aortic arteries is not related to genetic or hereditary, or acquired collagen disease, a genetic mutation in a certain component of the collagen fibers has been demonstrated, and the skin biopsy has shown some dermal dysplastic irregularity of the collagen fibers in concomitant with arterial dissection (Malfait et al., 2020). Thus, hereditary and genetic factors may contribute to arterial dissections in pregnancy patients. (d) Furthermore, previous studies have shown that the black race is one of the demographic characteristics and comorbid conditions of pregnancy-associated arterial dissections (Al-Hussaini, 2020; Ramlakhan et al., 2020), so ethnics can also be included as a confounding factor in the study. (e) Oxytocin antagonism can prevent pregnancy-associated aortic dissection in a mouse model of Marfan syndrome (Habashi et al., 2019). As thus, oxytocin use (and other drug use history) may be induced in the analysis. (f) Finally, other confounding factors related to arterial dissections in pregnant women include migraine, age at first childbirth, operation history, and infertility treatment (Collet et al., 2020). Including these risk factors in the further analysis would provide us more comprehensive information and improve our understanding, prevention, and treatment of pregnancyassociated arterial dissections.

\section{REFERENCES}

Adlam, D., Maas, A., Vrints, C., and Alfonso, F. (2016). Spontaneous coronary artery dissection. Eur. Heart J. 37, 3073-3074. doi: 10.1093/eurheartj/ehw467

\section{THE INCIDENCE AND MORTALITY TRENDS}

The authors discussed the location of arterial dissections during the peripartum period (pregnancy/delivery vs. postpartum), the total incidence and mortality of pregnancy-related arterial dissections, and the respective mortality of dissections at each site (Beyer et al., 2020). We also suggest analyzing the incidence and mortality trends of different types of dissections in pregnancy/delivery and postpartum over the course of the study period, respectively, in further study. Spontaneous cervical arterial dissection is the most common cause of ischemic stroke in North America in people younger than $45 \mathrm{yr}$ (Schievink et al., 1994). The disease has a pendular behavior from mild presentations that do not require further action (like Horner's syndrome) and resolve spontaneously to devastating large hemispheric infarcts (Beletsky et al., 2003). Women with Fibromuscular dysplasia are more predisposed to present with spontaneous cervical arterial dissections and occasionally with spontaneous coronary artery dissection (Hayes et al., 2018; Gornik et al., 2019). Thus, the incidence and mortality trends, as well as risk factor information for different types of arterial dissections, are also important. The complementary analysis may provide warning information, especially for the Center for Disease Control and Prevention.

\section{CONCLUSION REMARKS}

This study elicited pregnancy and non-pregnancy risk factors that predispose to arterial dissections in all stages of pregnancy and postpartum. Further complementary analysis of detailed risk factors and for different types of pregnancy-associated arterial dissections in different periods of pregnancy would provide some more substantially basic information to this field.

\section{AUTHOR CONTRIBUTIONS}

CD and XT prepared and submitted the manuscript. All authors read and approved the final manuscript.

\section{FUNDING}

This work was supported by the National Natural Science Foundation of China (grant numbers 81970426 and 81800273); the Young Elite Scientists Sponsorship Program of China Association for Science and Technology (grant number 2018QNRC001); the Scientific and Technological Innovation Talents Program of Sichuan Province (grant number 2020JDRC0017). 
Beyer, S. E., Dicks, A. B., Shainker, S. A., Feinberg, L., Schermerhorn, M. L., Secemsky, E. A., et al. (2020). Pregnancy-associated arterial dissections: a nationwide cohort study. Eur. Heart J. 41, 4234-4242. doi: 10.1093/eurheartj/ehaa497

Chen, X.-F., Chen, X., and Tang, X. (2020a). Short-chain fatty acid, acylation and cardiovascular diseases. Clin. Sci. 134, 657-676. doi: 10.1042/CS20200128

Chen, X.-F., Yan, L.-J., Lecube, A., and Tang, X. (2020b). Editorial: diabetes and obesity effects on lung function. Front. Endocrinol. 11:462. doi: 10.3389/fendo.2020.00462

Collet, J.-P., Thiele, H., Barbato, E., Barthélémy, O., Bauersachs, J., Bhatt, D. L., et al. (2020). 2020 ESC Guidelines for the management of acute coronary syndromes in patients presenting without persistent ST-segment elevation: the task force for the management of acute coronary syndromes in patients presenting without persistent ST-segment elevation of the European Society of Cardiology (ESC). Eur. Heart J. doi: 10.1093/eurheartj/ehaa624. [Epub ahead of print].

Gornik, H. L., Persu, A., Adlam, D., Aparicio, L. S., Azizi, M., Boulanger, M., et al. (2019). First international consensus on the diagnosis and management of fibromuscular dysplasia. Vasc. Med. 24, 164-189. doi: $10.1177 / 1358863 X 18821816$

Habashi, J. P., MacFarlane, E. G., Bagirzadeh, R., Bowen, C., Huso, N., Chen, Y., et al. (2019). Oxytocin antagonism prevents pregnancy-associated aortic dissection in a mouse model of Marfan syndrome. Sci. Transl. Med. 11:eaat4822. doi: 10.1126/scitranslmed.aat4822

Hayes, S. N., Kim, E. S. H., Saw, J., Adlam, D., Arslanian-Engoren, C., Economy, K. E., et al. (2018). Spontaneous coronary artery dissection: current state of the science: a scientific statement from the American Heart Association. Circulation 137, e523-e557. doi: 10.1161/CIR.0000000000000564

Katsuragi, S., Ueda, K., Yamanaka, K., Neki, R., Kamiya, C., Sasaki, Y., et al. (2011). Pregnancy-associated aortic dilatation or dissection in Japanese women with Marfan syndrome. Circ. J. 75, 2545-2551. doi: 10.1253/circj.CJ-11-0465

LeMaire, S. A., and Russell, L. (2011). Epidemiology of thoracic aortic dissection. Nat. Rev. Cardiol. 8, 103-113. doi: 10.1038/nrcardio.2010.187

Li, W.-P., Neradilek, M. B., Gu, F.-S., Isquith, D. A., Sun, Z.-J., Wu, X., et al. (2017). Pregnancy-associated plasma protein-A is a stronger predictor for adverse cardiovascular outcomes after acute coronary syndrome in type-2 diabetes mellitus. Cardiovasc. Diabetol. 16:45. doi: 10.1186/s12933-017-0526-6

Malfait, F., Castori, M., Francomano, C. A., Giunta, C., Kosho, T., and Byers, P. H. (2020). The Ehlers-Danlos syndromes. Nat. Rev. Dis. Primers 6:64. doi: 10.1038/s41572-020-0194-9

Ramlakhan, K. P., Johnson, M. R., and Roos-Hesselink, J. W. (2020). Pregnancy and cardiovascular disease. Nat. Rev. Cardiol. 17, 718-731. doi: 10.1038/s41569-020-0390-z

Schievink, W. I., Mokri, B., and O'Fallon, W. M. (1994). Recurrent spontaneous cervical-artery dissection. New. Engl. J. Med. 330, 393-397. doi: 10.1056/NEJM199402103300604

Tang, X., Li, P.-H., and Chen, H.-Z. (2020). Cardiomyocyte senescence and cellular communications within myocardial microenvironment. Front. Endocrinol. 11:280. doi: 10.3389/fendo.2020.00280

Theivacumar, N. S., Stephenson, M. A., Mistry, H., and Valenti, D. (2014). Diabetics are less likely to develop thoracic aortic dissection: a 10-year singlecenter analysis. Ann. Vasc. Surg. 28, 427-432. doi: 10.1016/j.avsg.2013.03.024

Timpka, S., Markovitz, A., Schyman, T., Mogren, I., Fraser, A., Franks, P. W., et al (2018). Midlife development of type 2 diabetes and hypertension in women by history of hypertensive disorders of pregnancy. Cardiovasc. Diabetol. 17:124. doi: 10.1186/s12933-018-0764-2

Tweet, M. S., Kok, S. N., and Hayes, S. N. (2018). Spontaneous coronary artery dissection in women: what is known and what is yet to be understood. Clin Cardiol. 41, 203-210. doi: 10.1002/clc.22909

Conflict of Interest: The authors declare that the research was conducted in the absence of any commercial or financial relationships that could be construed as a potential conflict of interest.

Copyright (c) 2021 Deng, Wang, Chen and Tang. This is an open-access article distributed under the terms of the Creative Commons Attribution License (CC BY). The use, distribution or reproduction in other forums is permitted, provided the original author(s) and the copyright owner(s) are credited and that the original publication in this journal is cited, in accordance with accepted academic practice. No use, distribution or reproduction is permitted which does not comply with these terms. 